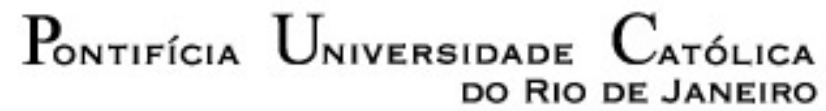

DO RIO DE JANEIRO

Frederico Jacobsen Junqueira

Negociadores Estratégicos Brasileiros e as Características do seu Estilo de Negociação

Dissertação de Mestrado

Dissertação apresentada ao programa de Pósgraduação em da PUC - Rio como requisito parcial para obtenção do título de Mestre em Administração..

Orientador: Prof. José Roberto Gomes da Silva 


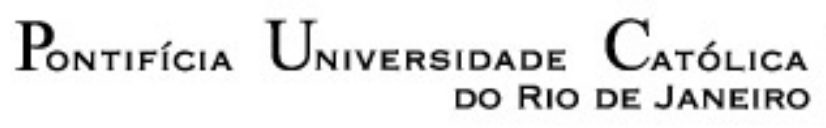

DO RIO DE JANEIRO

Frederico Jacobsen Junqueira

\title{
Negociadores Estratégicos Brasileiros e as \\ Características do seu Estilo de Negociação
}

Dissertação apresentada como requisito parcial para obtenção do grau de Mestre pelo Programa de Pós-Graduação em Administração da PUC-Rio. Aprovada pela Comissão Examinadora abaixo assinada.

\author{
Prof. José Roberto Gomes da Silva \\ Orientador \\ Departamento de Administração - PUC-Rio
}

Prof. Marco Aurelio Fagundes Albernaz

PUC-Rio

Profa. Mônica Zaidan Gomes Rossi

FACC/UFRJ

Prof. João Pontes Nogueira

Vice-Decano de Pós-Graduação do CCS

Rio de Janeiro, 18 de dezembro de 2007 
Todos os direitos reservados. É proibida a reprodução total ou parcial do trabalho sem autorização da universidade, do autor e do orientador.

Frederico Jacobsen Junqueira

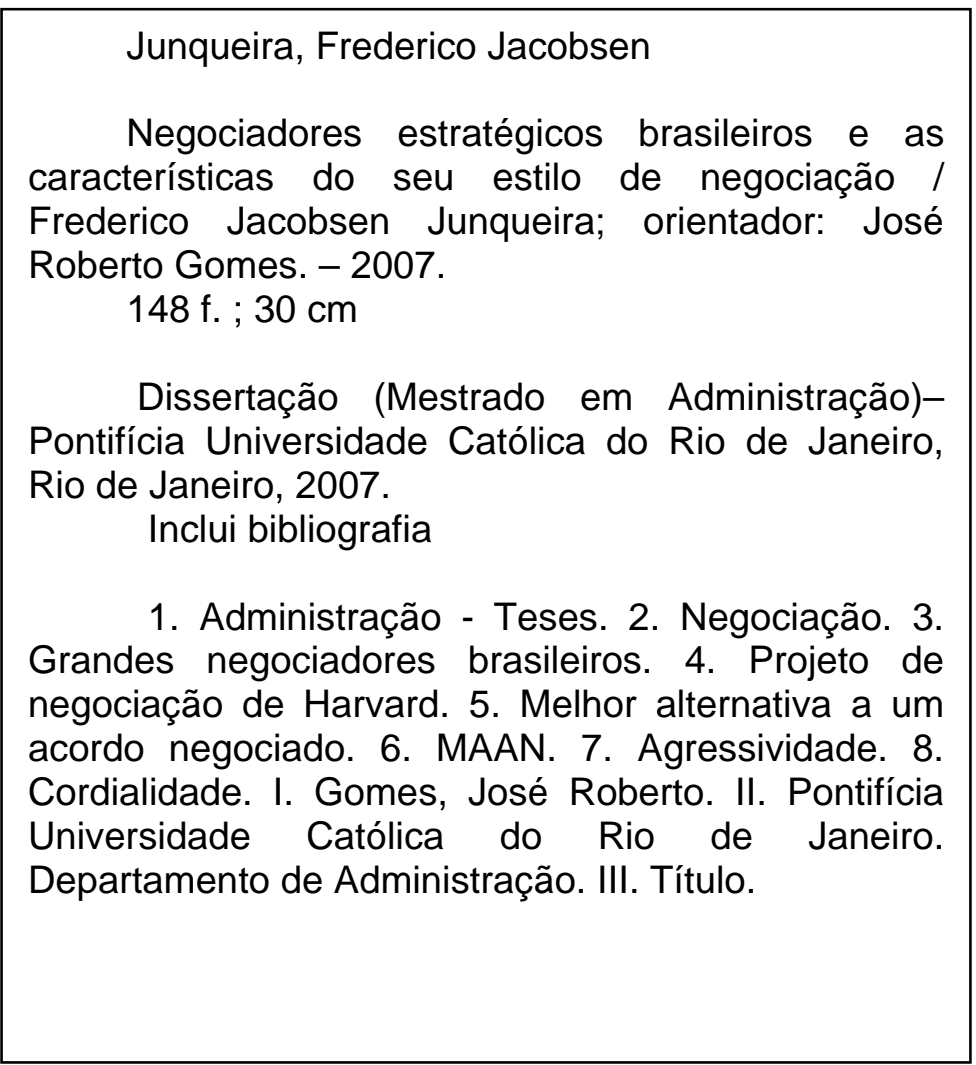




\section{Agradecimentos}

Ao meu orientador Professor José Roberto Gomes pelo incentivo, idéias e muitas horas de revisão necessárias para a realização deste trabalho.

Aos meus "sujeitos de pesquisa” que dedicaram precioso tempo de seus dias atarefados para que este trabalho pudesse ser realizado.

A Renata, pelo encorajamento e pela a paciência milenar chinesa necessária para conviver com um namorado em fase de produção de dissertação, junto com a construção de um negócio.

A meus irmãos por serem, antes de qualquer coisa, verdadeiros irmãos e fonte constante de amizade, amor e encorajamento.

A meu pai, Felipe, pelo exemplo diário do valor da honestidade, integridade, do trabalho e da persistência.

E a minha mãe, Andréa, pelo constante encorajamento intelectual, pela demonstração diária de persistência e determinação. E por ter dito "tudo o que você quiser comprar para ler, pode comprar” há quase três décadas atrás.

\section{Muito Obrigado}




\section{Resumo}

Junqueira, Frederico Jacobsen; Silva, José Roberto Gomes da. Negociadores Estratégicos Brasileiros e as Características do seu Estilo de Negociação. Rio de Janeiro, 2007. 148p. Dissertação de Mestrado Departamento de Departamento de Administração, Pontifícia Universidade Católica do Rio de Janeiro.

A capacidade de negociar efetivamente é considerada uma competência crítica na administração moderna (Ertel, 2000). A negociação é parte constante do dia a dia de qualquer ser humano e sua importância é ainda maior para o administrador, pois este utiliza a negociação nos mais variados aspectos e das mais variadas formas em seu dia a dia profissional. Aos estudantes e praticantes da administração brasileiros que desejem se aprofundar nas teorias e práticas de negociação, desenvolvidas dentro ou fora do país, restam poucos caminhos: a busca do auto conhecimento através de artigos e livros, cursos particulares dentro e fora do Brasil ou cursos em Universidades estrangeiras. Sendo assim, o objetivo principal deste trabalho é descobrir como negociadores estratégicos brasileiros praticam a negociação, englobando seus pontos positivos e negativos, além de tentar descobrir como estes negociadores encaram a negociação no Brasil e como essa prática se relaciona com a teoria de negociação. Este estudo buscará responder a algumas das seguintes perguntas, vistas sob o ponto de vista de grandes negociadores brasileiros: que relação tem a prática da negociação no Brasil com as teorias de negociação mais conhecidas? Será que as mesmas técnicas e táticas desenvolvidas e utilizadas nos Estados Unidos são utilizadas no Brasil? Esta pesquisa partiu da idéia de que seria interessante, numa tentativa de aumentar a efetividade do negociador brasileiro e baseado na falta de estudos desenvolvidos localmente, entender como alguns grandes negociadores nacionais praticam a negociação, o que gostam de usar e encontrar do outro lado da mesa, assim como o que não gostam.

\section{Palavras-chave}

negociação; grandes negociadores brasileiros; Projeto de Negociação de Harvard; melhor alternativa a um acordo negociado; MAAN; negociador brasileiro; agressividade;

cordialidade. 


\section{Abstract}

Junqueira, Frederico Jacobsen; Silva, José Roberto Gomes da (Advisor). Strategic Brazilian Negotiators: Characteristics of their way of negotiating. Rio de Janeiro, 2007. 148p. MSc. Dissertation - Departamento de Administração, Pontifícia Universidade Católica do Rio de Janeiro.

The ability to negotiate effectively is one the most crucial ones in today's business environment (Ertel, 2000). During his day to day a professional businessman or businesswoman will probably use negotiation on almost all aspects of any business. To the Brazilian professionals or students interested in deepening their knowledge of negotiation techniques there are only few paths available: self study, private courses both in and out of Brazil or negotiation courses in foreign Universities. That is one of the reasons why the main objective of this study is to shed some light on Brazilian strategic negotiators and their style, and also to try to find out what these negotiators think are the best and worst aspects of negotiating with Brazilians and foreigners. This work will try to answer the following questions, seen from the eyes of great Brazilian negotiators: what does the theory of negotiation used in Brazil have to do with the well-known international negotiation theories? Are the same techniques developed, mainly, in the United States used in Brazilian negotiations? One of the main ideas for this work is that, due to the lack of locally developed theories, it will be interesting to see how great Brazilian negotiators practice negotiation, what does their style have to do with well known theories and what do they like and dislike on a negotiation

\section{Keywords}

Negotiation; great Brazilian negotiators; Harvard Project on Negotiation; Better alternative to a negotiated agreement 


\section{Sumário}

1. Descrição do Problema 12

1.1. Introdução 12

1.2. Objetivo 14

1.3. Relevância da Pesquisa 15

1.4. Delimitação do Estudo 17

$\begin{array}{ll}\text { 1.5. Estrutura do Trabalho } & 18\end{array}$

2. As Teorias de Negociação e o Papel do Negociador 19

2.1. A Teoria de Negociação 19

2.2. A Problemática da Negociação 21

2.2.1. A Necessidade de se Negociar com os Próprios Sentimentos 22

2.2.2. A Conversa em Torno da Identidade 28

2.3. A Preparação para a Negociação 33

3. O Processo de Negociação 39

3.1. O Início da Negociação 39

3.2. Táticas e Técnicas ao Longo do Processo de Negociação 41

3.2.1. Intenção e Impacto 41

3.2.2. Culpa e o Sistema de Contribuição 43

3.2.3. Reação e Ponderação 46

3.2.4. O Passado e as Diferentes Visões 51

3.2.5. A Importância de Saber Ouvir 53

3.2.6. Posturas Tendenciosas 54

3.2.7. A Importância do Reconhecimento 62

3.2.8. A Importância de Concordar 65

3.2.9. O Desafio de Expressar Opiniões 66

3.2.10. Clareza e Transparência 69

3.2.11. A Reformulação de Problemas 70

3.2.12. A Necessidade de Lidar com os Truques 76

3.2.13. Negociar a Dinâmica da Negociação 78 
4. Escolhas e Resultados da Negociação 79

4.1. A Elaboração de Propostas 79

4.1.1. Entender a Escolha da Outra Parte 79

4.1.2. Brainstorming 82

4.2. O Fechamento de uma Negociação 83

4.2.1. A Geração de Bons Conselhos 88

4.2.2. A Utilização do Poder para Educar e não para Pressionar 89

4.2.3. Utilizar uma Terceira Parte 92

4.2.4. Fechar um Acordo Duradouro 95

4.3. Análise Pós-Negociação 96

5. Metodologia $\quad 97$

5.1. Pesquisa Qualitativa em Ciências Sociais 97

5.2. Tipo de Pesquisa 98

5.3. Seleção dos Entrevistados e Coleta de Dados 99

5.4. Tratamento e Análise dos Dados 103

5.5. Limitações do Método 103

$\begin{array}{ll}\text { 5.6. Perfis dos Entrevistados } & 104\end{array}$

6. Análise dos Resultados 108

6.1. Nível de Conhecimento Teórico Sobre Negociação 108

6.2. Importância de Reconhecer os Sentimentos por Trás das Posições da $\begin{array}{ll}\text { Outra Parte } & 109\end{array}$

6.3. A Concentração e o Controle Emocional Durante a Negociação 111

6.4. Da Utilização de Pausas 114

6.5. A Preparação para a Negociação 116

6.6. BATNA 119

6.7. Agressividade na Negociação 121

6.8. Comportamentos e Características dos Negociadores 122

6.9. A Outra Parte 124

6.10. Táticas de Negociação 126

6.11. Imagem da Outra Parte e Conclusão da Negociação 128

6.12. O Negociador Brasileiro 132 
7. Conclusão e Sugestões para Estudos Posteriores

7.1. Conclusões

7.2. Verificação dos Objetivos Propostos

7.3. Sugestões para Estudos Posteriores

7.4. Considerações Finais

8. Referências Bibliográficas 


\section{Lista de quadros}

Quadro 1 - Percepções Tendenciosas 55

Quadro 2 - Posições e Interesses $\quad 56$

Quadro 3 - Análise de Quatro Quadrantes para Resolução de Problemas 58

Quadro 4 - Guia para uma Sessão de Brainstorming 83

Quadro 5 - Perfis dos Entrevistados 105 
"La plus grande de découvertes ne consiste pás à chercher de nouveaux paysages, mais à changer de regard "

Marcel Proust (1871-1922) 